\title{
Particulate Matter Triggers for Pediatric Asthma
}

\author{
Batoul Chami $^{\mathrm{a}}$, Elizabeth Johnson ${ }^{\mathrm{a}}, \mathrm{J}_{\text {. Mike Courage }}{ }^{\mathrm{a}}$, Serge Danielson-Francois $^{\mathrm{a}}$
}

The exposure of particulate matter on children, ages $1-18$, is considered in this paper using a quantitative research approach. Utilizing foundational and seminal sources, this is a review of asthma and its triggers, and particulate matter, specifically ultrafine particles with a dimension of less than or equal to 100 nanometers (nm). An interest sparked with the effect of these ultrafine particles and their possible ignition of asthma. A troubling area was a lack of information on what may cause a greater link when exposed to these ultrafine particles: an ambient/indoor environment or an outdoor/non-ambient environment. This posed a significant concern because even though both environments may lead to asthma, the lack of information was not evident and not uninformed. To conduct this study, a systematic review occurred using a statistical program. Data was accumulated from multiple sources that tested for either an association of pediatric asthma and particulate matter with an outdoor exposure or an indoor exposure. Analyses were ran and statistical evidence resulted in a greater association in an indoor environment. The variables accounted for were odds ratio, confidence intervals and their limits, the setting of the tests run within the research and the exposure of the particulate matter.

Keywords: Ultrafine particles, Asthma, Particulate, Pediatric, Pollution, Urban Environments

\section{Introduction}

Asthma is a prominent lung disease in today's society that is significantly affecting people's lives, particularly children. Individuals who experience asthma are inflicted with a burden as there as triggers all around them in this world. Indoor or outdoor, asthma triggers are widely and commonly distributed and are minuscule for the human eye. The lacking barrier on this topic was which setting has a greater association with particulate matter and asthma, ambient or non-ambient, and to what extent. Many sources illustrated an association with each setting, but the line as to which imposes a greater danger is not clear. Children, who are considered "the most vulnerable," are affected by particulate matter and it's association with asthma more than adults because of their underdeveloped bodies, the time they spend in each setting, and their body compositions (Schüepp \& Sly, 2012). This led me to the question of: to what extent does particulate matter contribute to asthma including ambient and non-ambient air?

\section{What is Asthma?}

Asthma is a "disorder" that is affected by "airway hyperresponsiveness," caused by the buildup of mucus, and "bronchoconstriction." Asthma is lung disorder due to the mucus in the airway known as bronchi and bronchioles (Tsuang $\&$ Huang, 2012). When a person has asthma, their lungs inflate. The airways in the lungs become "twitchy" because exposures get into the lungs. Also, it is due to "widespread narrowing of airways due to the contraction of the airway muscle and the fluid accumulation in the tissue." A number of uncountable white blood cells also known as eosinophils enter the lungs causing inflammation. The results of the previously stated actions include chest tightness, wheezing, and breath shortness. According to the Society of Toxicology, asthma in the United States affects about 20 million people, including 6.7 million children (aged 1-18 years) ("Can All Those Chemicals Be Causing My Asthma?," n.d.). Research has illustrated that the most common childhood disease in the twenty-first century is asthma, especially in the industrialized world (Heinrich, 2011). Next, asthma could result from genetics and allergies. Allergies are affected by the "exposure to common environmental allergens such as pollen, cockroaches, dust mites, molds, pets and animals (especially birds)" and can trigger asthma. If allergies aren't the source, irritants also play a factor. Exposure to "cigarette smoke and pollution, cold air, exercise, stress and development of viral infections" can trigger asthma (Ho \& Kuschner, 2012). If exposure to these chemicals is continued over a long period of time, intense asthmatic symptoms arise. Even if you don't have allergies, asthma can be triggered by "high concentrations of irritating and reactive chemicals in the industrial settings" and can also be triggered by low concentrations due to the chemicals being an aggravation. Household cleaning products which contain chemicals ignite asthma. They reduce the amount of microbials and therefore there is "an alternation in the balance of the immune system." The hygiene hypothesis of asthma claims that "reduced exposure to infections and microbes at a young age (too clean) in developed countries shifts the immune system balance to favor development of allergies and asthma" (Schüepp \& Sly, 2012). To treat asthma, an inhaler or "inhaled drugs" will open up the airways and decrease the inflammation present.

\section{What are ultrafine particles?}

Research has illustrated an association with asthma and ultrafine particles. Airborne particles $\leq 0.1 \mu \mathrm{m}$ or 100 nanometers $(\mathrm{nm})$ are ultrafine particles. Ultrafine particles "can comprise a large number of particles in particulate matter with aerodynamic diameters $\leq 2.5 \mu \mathrm{m}\left(\mathrm{PM}_{2.5}\right)$." Ultrafine particles are produced through a combustion of biomass, such as cigarette smoke, or fossil fuels such as natural gas and diesel. Since ultrafine particles are a small portion of the "total mass" of $\mathrm{PM}_{2.5}$ and $\mathrm{PM}_{10}$, they encompass a significant majority of the "total particle count" of themselves (Heinzerling, Hsu, \& Yip, 2015). Particles that are smaller than $100 \mathrm{~nm}$ can evade human defense mechanisms and penetrate deep into an individual's body. After this they can reach the bloodstream and "accumulate in sensitive target sites such as bone marrow, lymph nodes, spleen, heart, brain, and the central nervous system" (Olvera \& et al., 2012). In the early 1980s, the notion of "human exposure" was defined as "an event that occurs when a person comes into contact with the pollutant" (Branco, Alvim-Ferraz, Martins, \& Sousa, 2014). Ultrafine particles can rapidly gather into a larger particle. Ultrafine particles' toxicity is significantly higher than larger particulate matter because of their small diameter, which allows the particles to "penetrate" extensively into the lungs more easier than larger particles. Secondly, ultrafine particles deposit into the alveoli, which are little air sacs within the lung that allow 
for a gas exchange and bronchioles, which are airway passages connected to the lung tissue at higher rates. Next, they are "cleared less efficiently from the respiratory tract than larger particles" and have a larger opportunity to "translocate" from the "lung into the bloodstream" and other organs and their systems. Lastly, ultrafine particles claim a larger surface area to mass ratio when compared to larger particles. This allows a bigger area for the ultrafine particles to absorb "potentially toxic chemicals or metals and interface with pulmonary surfaces" (Heinzerling, Hsu, \& Yip, 2015). Ambient air particles range in the ultrafine particles size. Ultrafine particles (UFPs) "dominate" surface area and in ambient air because of their small size (Chalupa, Morrow, Oberdörster, Utell, \& Frampton, 2004). Thus, there can be many particles causing a higher risk for children to inhale them, especially since they're more prone than adults. The health effects of particulate matter are affected by their "high surface area, oxidant capacity, ability to evade macrophage phagocytosis, and propensity for inducing pulmonary inflammation" (Chalupa, Morrow, Oberdörster, Utell, \& Frampton, 2004). $\mathrm{PM}_{2.5}$ and $\mathrm{PM}_{10}$, which provide a variation of harmful health effects are managed by the United States Environmental Protection Agency (EPA) as pollutants under the Clean Air Act (Heinzerling, Hsu, \& Yip, 2015). Airborne particles are components of indoor air. The occupations are joined with an heightened exposure to dust, pesticides, and air pollution (Schüepp \& Sly, 2012).

\section{Why Kids, not Adults?}

Children are the "most vulnerable group" when it comes to the harmful effects of nanoparticle exposure. This is due to their growing organs, behavioral disparities, and immature systems.Children's bodies enzyme systems and organs have still not completely grown, therefore making children weaker to particulate exposure when exposed to the environment. In regards to lung development, it begins early in gestation and continues into childhood. This goes on to prove as to why children are more vulnerable to particulate exposure, since their lungs aren't fully developed (Schüepp \& Sly, 2012). Toxicants, such as particulate matter can easily enter a child's lungs because the epithelium is thicker especially its first year. The epithelium acts as the gasblood barrier, and the barrier function does remain low for a child's first year. Unlike adults, children have a lower lung volume and their bodies occupy "a higher ratio between body surface area and body weight." Furthermore, children inhale at a minute ventilation $50 \%$ more than adults. Children have a higher "inhalation rate per kilogram of body weight than adults" (J. Lee, S. Lee, \& Bae, 2014). In regards to the biology of the lungs, most of the alveoli is created after birth, therefore causing long-term consequences, such as asthma. The minute ventilation and pulmonary surface area in proportion to body mass ratios, children's "potential effective pollutant dosage is higher than adults" (Heinzerling, Hsu, \& Yip, 2015). Concerning the growth deficiency of children's enzyme systems, the enzyme levels of Cytochrome P450 that resides in the neonatal lungs, are significantly lower than adult's levels. These characteristics make them more prone to inhale particulate matter than adults (Schüepp \& Sly, 2012). A recurrence of exposure of air pollutants may modify the travel path of "airway intervention." This causes an increased responsiveness to (environmental exposures) later in an individual's life that (may) lead to asthma and "decreased airway function" (Heinzerling, Hsu, \& Yip, 2015). 80\% of people spend their time indoors (Heinrich, 2011). Individuals, specifically children spend more time indoors than outdoors in this modern era. Research exemplified that in the United Kingdom, children spend more time within the home (19.3 hours per day, 80.4\%) than with mothers or fathers (18.4 and 14.7 hours per day) (J. Lee, S. Lee, \& Bae, 2014). Research has also illustrated that children aren't immune to "occupational exposure to nanoparticles. "Nanoparticles deposit mainly by diffusion and sedimentation thus deposition is mostly dependent on residential time, which is determined by breathing patterns" (J. Lee, S. Lee, \& Bae, 2014). Another factor that causes children to be more prone to particles is the fact they put "every-thing" into their mouths. This transmission of "every-thing" causes a rise to "non-nutritive ingestion of nanoparticles from the ground and in soil" (Schüepp \& Sly, 2012). Children's "air intake per weight unit in a resting infant is twice than in an adult." Children actively move from different locations throughout the day and are more exposed to a greater number of air contaminants for different periods of time (Branco, Alvim-Ferraz, Martins, \& Sousa, 2014).

\section{Question Explantation \& Significance of Topic}

I noticed a problem with pediatric asthma specifically with ultrafine particles in ambient air and non-ambient air. The literature has revealed a gap on what causes asthma, whether it be $\mathrm{PM}_{2.5}$ and $\mathrm{PM}_{10}$, indoor or outdoor. Asthma affects 20 million people, 6.7 million of whom are children ("Can All Those Chemicals Be Causing My Asthma?," n.d.). It is a predominant issue in our world today with the increase of individuals who have asthma and ultrafine particles dispersed all around us. Asthma doesn't just affect the individual who has it, but the individual's family is affected as well because there is a need to be cautious of the individual and their symptoms. There is a limitation for the individual as it limits everyday activities such as exercise. On a global perspective, asthma is fourteenth "based on the burden of disease." Asthma is significant because in the United States of America, asthma is apart of the health care costs. In 2012, "asthma was one of the 20 leading diagnosis groups for primary care visits." Moreover, asthma is the reason behind 1.8 million emergency room visits and 439,000 hospitalizations. Lastly, asthma can be fatal as it is one death for every 100,000 Americans ("Comment on Draft Reports and White Papers. Comment Draft Reports," n.d.). There are approximately 325,000,000 Americans ("U.S. and World Population Clock," n.d.). That is about 3,250 asthma deaths a year.

\section{Methodology}

I began with reading multiple sources that I got from the University of Michigan Dearborn Mardigian database, the University of Michigan Library Ann Arbor database, and the Wayne State University database. I read peer-reviewed journal articles and foundational sources to get background information on asthma, as I deal with the disease and was interested in it. I shifted through roughly 52 peer-reviewed journal articles to find my common desired values. I resulted with 15 peer-reviewed journal articles that provided me with data (Klot et al., 2002) (Andersen, Wahlin, Raaschou-Nielsen, \& Scheike, 2007) (Delfino, Gong, Linn, Pellizzari, \& Hu, 2002) (Slaughter, Lumley, Sheppard, Koenig, \& Shapiro, 2003) (Jalaludin, O’Toole, \& Leader, 2004) (Yu, Sheppard, Lumley, Koenig, \& Shapiro, 2000) (Schildcrout, 2006) (Brauer et al., 2002) (Janssen et al., 2003) (Zheng et al.,2015) (Lim et al., 2016) (Iskandar et al., 2011) (Pénard-Morand et al., 2010) (Hwang, Lee, Lin, Jaakkola, \& Guo., 2005) (Morgenstern, Heinrich, Zutavern, Cyrys, \& Brockow, 2008). After going through the sources, I saw a connection with ultrafine 
particles. I chose asthma because I experience the prominent lung disease. Research illustrated that children this era spend more time indoors than outdoors, so research that accounted for an indoor environment was my goal. I noticed that ultrafine particles less than $100 \mathrm{~nm}$ caused a significant effect in asthma.

Furthermore, I excised multiple sources based on their odd ratio values and confidence intervals. All the sources I choose must have a confidence interval of $95 \%$. Indeed, some sources had risk ratios that I had to convert into odds ratio. I used a mathematical formula:

("How to convert odds ratio to relative risks," 2014).

I translated this formula into terms where the odds ratio (OR) would be the outcome, not the risk ratio (RR). Therefore, I ended with this formula:

The odds ratio (OR) is the a measure of association between an exposure and an outcome. The odds ratio (OR) shows the odds an outcome will happen with a specific exposure. It is contrasted to the odds of the end result happening in the absence of that exposure (Szumilas, 2010). Risk ratio (RR) is a measurement illustrating the risk of a "certain event happening in one group compared to the risk of the same event happening in another group" ("NCI Dictionary of Cancer Terms," n.d.). The p-value measures the probability an outcome will occur (Hunt, 1999) (Vogt, 2006) (Knaflic, 2015) (Popper, 2002).

Table 1. Studies and their values before and after the conversion using the formula above.

Risk Ratios to Odds Ratio Converted and Calculated Values

\begin{tabular}{|l|l|l|l|}
\hline Study & p-Value & Risk Ratios & $\begin{array}{l}\text { Converted Odds Ratio } \\
\text { Value }\end{array}$ \\
\hline Andersen et al., 2007 & 0.05 & 1.077 & 1.085 \\
\hline Lim et al., 2016 & 0.42 & 1.048 & 1.122 \\
\hline Zheng et al., 2015( $\left.\mathrm{PM}_{2.5}\right)$ & 0.06 & 1.023 & 1.026 \\
\hline Zheng et al., 2015 $\left(\mathrm{PM}_{10}\right)$ & 0.001 & 1.010 & 1.010 \\
\hline
\end{tabular}

I conducted two separate meta analyses using Comprehensive Meta Analysis ("Comprehensive Meta-Analysis," 2015). I coded the studies by placing them into two categories: "indoor" and "outdoor." One trial focused on asthma possibly caused by ambient (or indoor) air particles, and the second trial focused on asthma perhaps caused by outdoor air particles. When I shifted through my sources, I saw a commonality with the odds ratio. To decide whether an article fit in the "outdoor category" or "indoor category," I had prerequisites set where I made a rational decision based on the information provided in the sources' methods sections. For the indoor category, common keywords that allowed them to be placed within that group included: "ambient," "indoor," "inside," and "within." For the outdoor category, common keywords included: "outdoor," "urban," and "outside." In addition, to supplement my decision making process, the setting of the study and data collection played a role, as well as what was being measured, such as particulate matter 2.5 and $10 \mathrm{~nm}$. For example, if the young test subjects were being measured from walking through the city, such as to school or to their homes, then they were placed into the "outdoor category." Of my initial fifteen sources, nine sources were placed in the "indoor category" and six articles were in the "outdoor category."

The statistical significance (numerical value of $\mathrm{z}$ ) was found. As a result, I achieved a conclusion with the data that came out of the meta analysis program. I examined the variability in distribution of the weighed values. In the end, I interpreted the results. I am doing meta-analysis because it gives me the most accurate data, and to reject randomness. Meta analysis allows me to synthesize sources in order to develop an argument in medicine about asthma. Moreover, tests can be run on the sources I have available to act as my research project.

\section{Results}

After I ran analyses, weighted values were calculated. The values computed for the "indoor category" were a p-value of 0.000 meaning I can reject the null hypothesis, which means there is no possible link between an indoor environment and particulate matter leading to asthma. My original hypothesis was particulate matter causing asthma in an indoor environment, and the null would counter that. Therefore statistical evidence has illustrated that there is a possible link. A low p-value rejects the null hypothesis, and this applies with the "outdoor category." The second analysis outputted a p-value of 0.078 , therefore I can reject the null hypothesis because in statistics a p-value lower than 0.1 shows no significance. My null hypothesis was there being no possible link between an outdoor environment and particulate matter therefore not leading to asthma. This shows significance in my original hypothesis, which is there is a link between an outdoor environment and particulate matter therefore leading to asthma. My original hypothesis would apply here, and statistical evidence supports the link of an outdoor environment and particulate matter may lead to asthma.

In regards to the odds ratio, the "indoor category" resulted with a value of 1.114. The exposure in this case is the indoor environment with the ambient air particles, the outcome is asthma, and the odds are how likely asthma will occur within the indoor environment being exposed by the particulate matter. In regards to the "outdoor category," a value of 1.053 resulted. The 
outcome remains constant except the exposure changes into an outdoor environment and the odds changes into how likely asthma will occur within the outdoor environment being exposed by the particulate matter. According to the NCBI, an odds ratio greater than a value of 1 means the "exposure associated with higher odds of outcome" (Szumilas, 2010). Both categories resulted with values higher than one, so in both, an indoor and outdoor environment may link to asthma. However, since the "indoor category" resulted with a value of 1.114 , higher than the "outdoor category" with a value of 1.053 , an indoor environment would have a greater association with asthma. The particulate matter that is exposed from an indoor environment poses a greater degree of the possibility of asthma triggered.

Table 2. The computed meta analysis of the "indoor category." The last row is the final values for each variable (odds ratio, lower limit, upper limit, z-value, and p-value).

\section{Indoor Category}

\begin{tabular}{|c|c|c|c|c|c|}
\hline Study & Odds Ratio & Lower Limit & Upper Limit & Z-Value & $\mathrm{p}$-Value \\
\hline Delfino et al., 2003 & 1.450 & 1.108 & 1.897 & 2.710 & 0.007 \\
\hline$\left(\mathrm{PM}_{10}\right)$ Slaughter et al., 2003 & 1.110 & 1.033 & 1.193 & 2.833 & 0.005 \\
\hline$\left(\mathrm{PM}_{2.5}\right)$ Slaughter et al., 2003 & 1.160 & 1.033 & 1.303 & 2.499 & 0.012 \\
\hline Jalaludin et al., 2004 & 1.100 & 1.018 & 1.188 & 2.424 & 0.015 \\
\hline Yu et al., 2000 & 1.090 & 1.008 & 1.178 & 2.172 & 0.030 \\
\hline Brauer et al., 2002 & 1.120 & 0.838 & 1.497 & 0.766 & 0.444 \\
\hline \multirow[t]{2}{*}{ Janssen et al., 2003} & 1.030 & 0.586 & 1.809 & 0.103 & 0.918 \\
\hline & 1.114 & 1.070 & 1.159 & 5.306 & 0.000 \\
\hline
\end{tabular}

Table 3. The computed meta analysis of the "outdoor category." The last row is the final values for each variable (odds ratio, lower limit, upper limit, z-value, and p-value).

Outdoor Category

\begin{tabular}{|l|l|l|l|l|l|}
\hline Study & Odds Ratio & $\begin{array}{l}\text { Lower } \\
\text { Limit }\end{array}$ & Upper Limit & Z-Value & p-Value \\
\hline$\left(\mathrm{PM}_{10}\right)$ Iskanadar et al., 2011 & 1.090 & 1.003 & 1.184 & 2.041 & 0.041 \\
\hline$\left(\mathrm{PM}_{2.5}\right)$ Iskanadar et al., 2011 & 1.020 & 0.943 & 1.103 & 0.494 & 0.621 \\
\hline & 1.053 & 0.994 & 1.114 & 1.764 & 0.078 \\
\hline
\end{tabular}

In regards to the $\mathrm{Z}$-value, it is the measure of the standard deviation ("What is a $\mathrm{Z}$ score What is a p-value," n.d.). The standard deviation is a measure of how much discrepancy there is in my data. Since my results outputted a z-value of 1.764 for the outdoor category, it is +1.764 standard deviations away from the mean. For the indoor category, a $\mathrm{z}$-value of 5.306 returned. Since I got a low z-value, or low variation and a low p-value for the outdoor environments, it is very unlikely that what data was observed in the meta analysis is represented by null hypothesis. Moreover, this applies to the indoor category since I got a low pvalue and a high z-value, meaning the null hypothesis doesn't support ("What is a Z score What is a p-value," n.d.). Since both, the indoor and outdoor environments p-values rejected their null hypotheses, statistical evidence supported by the z-values allows me to reject the null hypotheses for a second time. This shows again that both an indoor and outdoor environment may lead to asthma because of the particulate matter triggers exposed within those settings.

\section{Solutions}

Recent studies have found that "increased levels" of exhaled nitric oxide (FeNO) has shown shown to predict asthma in children. Airway inflammation occurs, just as in asthma. Early subclinical inflammation can be targeted, as testing for FeNO would be essential. High levels of FeNO are present before asthmatic symptoms, so asthma would be targeted and treated. In past studies, FeNO has been used with children to determine exposures and their effects. An association with $\mathrm{PM}_{2.5}$ and $\mathrm{PM}_{10}$ and increased levels in FeNO has been seen with asthmatic and urban-dwelling children. Measurements could be taken by using a "flow rate $50 \mathrm{~mL} / \mathrm{s}$ (FENO50) using Niox Mino" as a recent study did (Carlsen, Boman, Björ, Olin, \& Forsberg, 2016). It could be measured in schools, just as eye and hearing exams are conducted. Another option is a measurement could be at doctor 
appointments. It would be a quick add onto the pre-requisites that occur like a check of weight, height, nose, ears, and mouth. Hospital admissions performing this test on children would be beneficial and provide no harm as it is added to the pre-requites just like at the doctor's office. The government could fund and provide these machines. This will allow for an early spotting of asthma, so precautionary actions could take place like removing common triggers within a home.

Another possible solution is reducing common home triggers for asthma. Some home triggers include: allergens, irritants, and household cleaning products (Ho \& Kuschner, 2012). Allergies trigger asthma, and some allergens include pets. If pets could be removed, asthma may be less prompted. Irritants, such as pollution, cigarette smoke, and fossil fuels provoke asthma. Preventing or eliminating smoking in the home can be a possible solution and eliminating pollution. Fossil fuels can be limited in an indoor environment by for example, not using a coal or gas stove. Instead, an electric stove might be a more effective option. Thirdly, limiting household cleaning products or switching to organic cleaning products will perhaps not be likely to trigger asthma as much.

\section{Limitations}

A prominent limitation of my study was faced when meta analysis was conducted. I had fifteen sources of data, however, once imputed into the program, eight sources weren't able to be factored into the whole computed analysis (as seen in appendices section, table $1 A$ and $1 B$, in red). This was because the values in the "lower" and "upper" limits for the confidence interval were too low of values to be considered for the analysis. This was an issue that couldn't have been foreseen before I ran the analyses, and had to utilize the data that was provided to me and to the research community at the time being. Although my data wasn't as packed with as many sources as I would have liked to have, results were still achieved.

Another limitation is in regards to my solutions section, I understand we can't eliminate pollution since it's in an outdoor environment and nature cannot be controlled. However, eliminating it or moving away from the pollution is unrealistic but an achievable idea. I do acknowledge that not everyone will stop driving their cars, and relocating away from a factory isn't ideal, but if it can happen, why not make the switch to reduce asthma triggers. There is little we can do to remove particulate matter outdoors, but other triggers indoors could be removed, where people spend $80 \%$ of their indoors (Heinrich, 2011). Thus, a near elimination from one environment may decrease the likelihood of asthma and the presence of exposure to particulate matter. An attempt in decreasing indoor triggers would be beneficial as my data has illustrated, an indoor environment has a greater effect to trigger asthma.

This study did not fully account for the codification of the sources (indoor, outdoor). I coded the studies that provided data based off their common keywords, and the setting of the conducted study. I do acknowledge that I used my own rational to decide which category the study gets placed into. This does allow for a possible error, since I didn't get more than one decision from others, so there was no ultimate consensus. There is no $100 \%$ guarantee that each study was categorized correctly, since others may have differing opinions on the categorization process. Furthermore, this study doesn't separate $\mathrm{PM}_{10}$ and $\mathrm{PM}_{2.5}$. I compiled both sizes into each category: ambient and non-ambient. This doesn't provide the most accurate data where a step can be taken further to see which particulate matter in which environment, indoor or outdoor will have a greater effect.

Lastly, this study conducts a quantitative research method, which has some setbacks. Although my values are constant, and a constant effects size was calculated, meta analysis is seen to "ignore" the fact that treatments do indeed vary from different studies. Qualitative wouldn't work as meta analysis synthesis the effect size, and does not provide a summary on the effect size. Another issue is I cannot account for which studies that provide this study data and information are biased. There is a possibility that some sources in this study are biased, but this is not and can't be known. If meta analysis were to be conducted on biased studies, then the data reported will reflect the bias.

\section{Future Research}

In the future, I would address the limitation of my categorization. I would implement a wide panel of people within different fields to help find a universal answer when it comes to each individual study and data set. This allows for a non rational decision that is supported by many backgrounds and and allows for a greater confidence in the categorization of the data.

Moreover, if I had unlimited resources and more time, I would conduct my own research project, gathering my own data. I wouldn't use other sources and perform a systematic meta analysis, as I believe my own research would be more significant. I would attach monitors onto the young test subjects, and watch closely their daily inhalants indoor and outdoor. With the new research on FeNO, I would test the association of it with the two environments: indoor and outdoor. FeNO might be like particulate matter and cause inflammation in the lungs, but it's association in the two environments is unknown.

New pathways of research include the association between FeNO acting as a marker for early onset asthma in children. An area of concern would be which environment has a greater association with asthma and the particulate matter on adults. Another issue would be what role do the other asthma triggers play. For example, which trigger has a greater effect, household cleaning products with the chemicals they contain or pollution? The effect of multiple triggers for asthma being exposed at the same time is lacking in research. We may know what one trigger may do in a certain environment, but multiple may pose as a higher risk to developing asthma

\section{Conclusion}

This study took into account the key issue of pediatric asthma and its association with ultrafine particles. This study took a step further to look into which environment had a greater association when exposed to particulate matter: an indoor or an outdoor environment. The review of literature addressed what is asthma, ultrafine particles, and why children are considered the most vulnerable group. This study coded data into two categories: indoor or outdoor based off of the setting of the research being conducted. The results concluded from the meta analysis program allowed for the rejection of my null hypotheses, showing an association with both environments. Both studies were supported by a z-value, where again the null hypothesis did not represent the data. However, a larger odds ratio, the results suggest a greater association with an indoor environment when particulate matter exposure is present. 


\section{References}

Andersen, Z. J., Wahlin, P., Raaschou-Nielsen, O., Scheike, T., \& S. (2006). Ambient Particle Source Apportionment and Daily Hospital Admissions among Children and Elderly in Copenhagen. Epidemiology, 17(Suppl). doi:10.1097/00001648-200611001-0051

Branco, P., Alvim-Ferraz, M., Martins, F., \& Sousa, S. (2014). The microenvironmental modelling approach to assess childrens exposure to air pollution - A review. Environmental Research, 135, 317-332. doi:10.1016/j.envres.2014.10.002

Brauer, M., Hoek ,G., Vliet, P. V., Meliefste, K., Fischer, P. H., Wijga, A., . . Brunekreef, B. (2002). Air Pollution from Traffic and the Development of Respiratory Infections and Asthmatic and Allergic Symptoms in Children. American Journal of Respiratory and Critical Care Medicine, 166(8), 1092-1098. doi:10.1164/rccm.200108-007oc

Can All Those Chemicals Be Causing My Asthma? . (n.d.). Retrieved December 3, 2016, from https://www.toxicology.org/script/admin/toxtopics/114605_AM_TT1_Asthma.pdf.

Carlsen, H., Boman, P., Björ, B., Olin, A., \& Forsberg, B. (2016). Coarse Fraction Particle Matter and Exhaled Nitric Oxide in Non-Asthmatic Children. International Journal of Environmental Research and Public Health, 13(6), 621. doi:10.3390/ijerph1306062.

Chalupa, D. C., Morrow, P. E., Oberdörster, G., Utell, M. J., \& Frampton, M. W. (2004). Ultrafine Particle Deposition in Subjects with Asthma. Environmental Health Perspectives, 112(8), 879-882. doi:10.1289/ehp.6851 Comment on Draft Reports and White Papers. Comment Draft Reports | AHRQ Effective Health Care Program. (n.d.).

Comprehensive Meta-Analysis. (2015, January 01). Retrieved April 22, 2017, from https://www.meta-analysis.com/. Retrieved April 20, 2017, from https://effectivehealthcare.ahrq.gov/research-available-for-comment/comment-draftrepor ts/?pageaction=displaydraftcommentform\&topicid=645\&productid=2464\&documenttype =draftRepor

Delfino, R. J., Gong, H., Linn, W. S., Pellizzari, E. D., \& Hu, Y. (2002). Asthma Symptoms in Hispanic Children and Daily Ambient Exposures to Toxic and Criteria Air Pollutants. Environmental Health Perspectives, 111(4), 647-656. doi:10.1289/ehp.5992

Heinrich, J. (2011). Influence of indoor factors in dwellings on the development of childhood asthma. International Journal of Hygiene and Environmental Health, 214(1), 1-25. doi:10.1016/j.ijheh.2010.08.00

Heinzerling, A., Hsu, J., \& Yip, F. (2015). Respiratory Health Effects of Ultrafine Particles in Children: a Literature Review. Water, Air, \& Soil Pollution, 227(1). doi:10.1007/s11270-015-2726-6

Ho, L. A., \& Kuschner, W. G. (2012). Respiratory Health in Home and Leisure Pursuits. Clinics in Chest Medicine, 33(4), 715-729. doi:10.1016/j.ccm.2012.08.001

How to convert odds ratios to relative risks. (2014, January 27). Retrieved April 20, 2017, from https://robertgrantstats.wordpress.com/2014/01/27/how-to-convert-odds-ratios-to-relative-risks/.

Hunt, M. (1999). How science takes stock: the story of meta-analysis. New York, NY: Russell Sage Foundation.

Hwang, B. (2005). Traffic related air pollution as a determinant of asthma among Taiwanese school children. Thorax, 60(6), 467-473. doi:10.1136/thx.2004.033977

Iskandar, A., Andersen, Z. J., Bønnelykke, K., Ellermann, T., Andersen, K. K., \& Bisgaard, H. (2011). Coarse and fine particles but not ultrafine particles in urban air trigger hospital admission for asthma in children. Thorax, 67(3), 252257. doi:10.1136/thoraxjnl-2011-200324

Jalaludin, B. B., O'Toole, B. I., \& Leeder, S. R. (2004). Acute effects of urban ambient air pollution on respiratory symptoms, asthma medication use, and doctor visits for asthma in a cohort of Australian children. Environmental Research, 95(1), 32-42. doi:10.1016/s0013-9351(03)00038-0

Janssen, N. A., Brunekreef, B., Vliet, P. V., Aarts, F., Meliefste, K., Harssema, H., \& Fischer, P. (2003). The

Relationship between Air Pollution from Heavy Traffic and Allergic Sensitization, Bronchial Hyperresponsiveness, and Respiratory Symptoms in Dutch Schoolchildren. Environmental Health Perspectives, 111(12), 1512-1518. doi:10.1289/ehp.6243

Klot, S. V., Wolke, G., Tuch, T., Heinrich, J., Dockery, D., Schwartz, J., . . Peters, A. (2002). Increased asthma medication use in association with ambient fine and ultrafine particles. European Respiratory Journal, 20(3), 691-702. doi:10.1183/09031936.02.01402001

Knaflic, C. N. (2015). Storytelling with data: a data visualization guide for business professionals. Hoboken, NJ: Wiley.

Lee, J. Y., Lee, S., \& Bae, G. (2014). A review of the association between air pollutant exposure and allergic diseases in children. Atmospheric Pollution Research, 5(4), 616-629. doi:10.5094/apr.2014.071

Lim, H., Kwon, H., Lim, J., Choi, J. H., Ha, M., Hwang, S., \& Choi, W. (2016). Short-term Effect of Fine Particulate Matter on Children's Hospital Admissions and Emergency Department Visits for Asthma: A Systematic Review and Meta-analysis. Journal of Preventive Medicine and Public Health, 49(4), 205-219. doi:10.3961/jpmph.16.037

Morgenstern, V., Heinrich, J., Zutavern, A., Cyrys, J., \& Brockow, I. (2007). Atopic Diseases, Allergic Sensitization, and Individual Estimated Exposure to Traffic-Related Air Pollutants in Children. Epidemiology, 18(Suppl). doi:10.1097/01.ede.0000276436.22928.f1

NCI Dictionary of Cancer Terms. (n.d.). Retrieved April 26, 2017, from https://www.cancer.gov/publications/dictionaries/cancer-terms?cdrid=618614.

Olvera, H. A., Perez, D., Clague, J. W., Cheng, Y., Li, W., Amaya, M. A., . .Pingitore, N. E. (2012). The Effect of Ventilation, Age, and Asthmatic Condition on Ultrafine Particle Deposition in Children. Pulmonary Medicine, 2012, 1 9. doi:10.1155/2012/736290

Penard-Morand, C., Raherison, C., Charpin, D., Kopferschmitt, C., Lavaud, F., Caillaud, D., \& Annesi-Maesano, I. (2010). Long-term exposure to close-proximity air pollution and asthma and allergies in urban children. European Respiratory Journal, 36(1), 33-40. doi:10.1183/09031936.00116109 
Popper, K. (2002). Popper: the logic of scientific discovery. London: Routledge Classics.

Schildcrout, J. S. (2006). Ambient Air Pollution and Asthma Exacerbations in Children: An Eight-City Analysis. American Journal of Epidemiology, 164(6), 505-517. doi:10.1093/aje/kwj225

Schüepp, K., \& Sly, P. D. (2012). The developing respiratory tract and its specific needs in regard to ultrafine particulate matter exposure. Paediatric Respiratory Reviews, 13(2), 95-99. doi:10.1016/j.prrv.2011.08.00

Slaughter, J. C., Lumley, T., Sheppard, L., Koenig, J. Q., \& Shapiro, G. G. (2003). Effects of ambient air pollution on symptom severity and medication use in children with asthma. Annals of Allergy, Asthma \& Immunology, 91(4), 346353. doi:10.1016/s1081-1206(10)61681-x

Szumilas, M. (2010). Explaining Odds Ratios. Journal of the Canadian Academy of Child and Adolescent Psychiatry. Retrieved April 22, 2017, from https://www.ncbi.nlm.nih.gov/pmc/articles/PMC2938757/.

Tsuang, W., \& Huang, Y. T. (2012). Asthma Induced by Exposure to Spray Polyurethane Foam Insulation in a Residential Home. Journal of Occupational and Environmental Medicine, 54(3), 272-273. doi:10.1097/jom.0b013e31824d2da1

U.S. and World Population Clock Tell us what you think. (2017, April 27). Retrieved July 31, 2017, from https://www.census.gov/popclock/

Vogt, W. P. (2007). Quantitative research methods for professionals. Boston, MA: Pearson/Allyn and Bacon.

What is a Z score What is a p-value. What is a Z score What is a p-value. (n.d.). Retrieved April 22, 2017, from $\mathrm{http} / / /$ resources.esri.com/help/9.3/arcgisdesktop/com/gp_toolref/spatial_statistics_toolbox/what_is_a_z_score_what_is_ a_p_value.htm.

Yu, O., Sheppard, L., Lumley, T., Koenig, J. Q., \& Shapiro, G. G. (2000). Effects of Ambient Air Pollution on Symptoms of Asthma in Seattle-Area Children Enrolled in the CAMP Study. Environmental Health Perspectives, 108(12), 1209. doi:10.2307/3434835

Zheng, X., Ding, H., Jiang, L., Chen, S., Zheng, J., Qiu, M., . . Guan, W. (2015). Association between Air Pollutants and Asthma Emergency Room Visits and Hospital Admissions in Time Series Studies: A Systematic Review and MetaAnalysis. Plos One, 10(9). doi:10.1371/journal.pone.0138146 


\section{Appendices}

Table 1A. Data that was inputted into the meta analysis program before results. Low "limits" are in red. Indoor Category Including "Too Low" Limits

\begin{tabular}{|l|l|l|l|l|}
\hline Study & Odds Ratio & Lower Limit & Upper Limit & Confidence Level \\
\hline Klot et al., 2002 & 0.920 & 0.860 & 1.000 & 0.950 \\
\hline Andersen et al., 2007 & 1.085 & 1.004 & 1.155 & 0.950 \\
\hline Delfino et al., 2003 & 1.450 & 1.110 & 1.900 & 0.950 \\
\hline$\left(\mathrm{PM}_{10}\right)$ Slaughter et al., 2003 & 1.110 & 1.030 & 1.190 & 0.950 \\
\hline$\left(\mathrm{PM}_{2.5}\right)$ Slaughter et al., 2003 & 1.160 & 1.030 & 1.300 & 0.950 \\
\hline Jalaludin et al., 2004 & 1.100 & 1.020 & 1.190 & 0.950 \\
\hline Yu et al., 2000 & 1.090 & 1.010 & 1.180 & 0.950 \\
\hline Schildcrout et al., 2006 & 1.020 & 0.980 & 1.070 & 0.950 \\
\hline Brauer et al., 2002 & 1.120 & 0.840 & 1.500 & 0.950 \\
\hline Janssen et al., 2003 & 1.030 & 0.590 & 1.820 & 0.950 \\
\hline
\end{tabular}

Table 2A. After analyses were ran for "indoor environment." The empty boxes are lacking in data because of the "low limits" which didn't allow for data to be outputted.

Indoor Category Including "Too low" Limits (after analyses ran)

\begin{tabular}{|l|l|l|l|}
\hline Study & Odds Ratio & Log Odds Ratio & Standard Error \\
\hline Klot et al., 2002 & & & \\
\hline Andersen et al., 2007 & & & \\
\hline Delfino et al., 2003 & 1.450 & 0.372 & 0.137 \\
\hline$\left(\mathrm{PM}_{10}\right)$ Slaughter et al., 2003 & 1.110 & 0.104 & 0.037 \\
\hline$\left(\mathrm{PM}_{2.5}\right)$ Slaughter et al., 2003 & 1.160 & 0.148 & 0.059 \\
\hline Jalaludin et al., 2004 & 1.100 & 0.095 & 0.039 \\
\hline Yu et al., 2000 & 1.090 & 0.086 & 0.040 \\
\hline Schildcrout et al., 2006 & & & \\
\hline Brauer et al., 2002 & 1.120 & 0.113 & 0.148 \\
\hline Janssen et al., 2003 & 1.030 & 0.000 & 0.287 \\
\hline
\end{tabular}


Table 1B. Data that was inputted into the meta analysis program before results. Low "limits" are in red. Outdoor Category Including "Too Low" Limits

\begin{tabular}{|l|l|l|l|l|}
\hline Study & Odds Ratio & Lower Limit & Upper Limit & Confidence Level \\
\hline$\left(\mathrm{PM}_{10}\right)$ Zheng et al., 2015 & 1.010 & 1.008 & 1.013 & 0.950 \\
\hline$\left(\mathrm{PM}_{2.5}\right)$ Zheng et al., 2015 & 1.026 & 1.015 & 1.031 & 0.950 \\
\hline Lim et al., 2016 & 1.122 & 1.028 & 1.067 & 0.950 \\
\hline$\left(\mathrm{PM}_{10}\right)$ Iskandar et al., 2011 & 1.090 & 1.000 & 1.180 & 0.950 \\
\hline$\left(\mathrm{PM}_{2.5}\right)$ Iskandar et al., 2011 & 1.020 & 0.940 & 1.100 & 0.950 \\
\hline Penard-Morand et al., 200... & 1.280 & 1.060 & 1.510 & 0.950 \\
\hline Hwang et al., 2005 & 0.930 & 0.910 & 0.960 & 0.950 \\
\hline Morgenstern et al., 2008 & 1.120 & 0.940 & 1.290 & 0.950 \\
\hline
\end{tabular}

Table 2B. After analyses were ran for "outdoor environment." The empty boxes are lacking in data because of the "low limits" which didn't allow for data to be outputted.

Indoor Category Including "too low" Limits (after analyses ran)

\begin{tabular}{|l|l|l|l|}
\hline Study & Odds Ratio & Log Odds Ratio & Standard Error \\
\hline$\left(\mathrm{PM}_{10}\right)$ Zheng et al., 200... & & & \\
\hline$\left(\mathrm{PM}_{2.5}\right)$ Zheng et al., 200.. & & & \\
\hline Lim et al., 2016 & & & \\
\hline$\left(\mathrm{PM}_{10}\right)$ Iskandar et al., 200... & 1.090 & 0.086 & 0.042 \\
\hline$\left(\mathrm{PM}_{2.5}\right)$ Iskandar et al., 200... & 1.020 & 0.020 & 0.040 \\
\hline Penard-Morand et al., 2010 & & & \\
\hline Hwang et al., 2005 & & & \\
\hline Morgenstern et al., 2008 & & & \\
\hline
\end{tabular}

